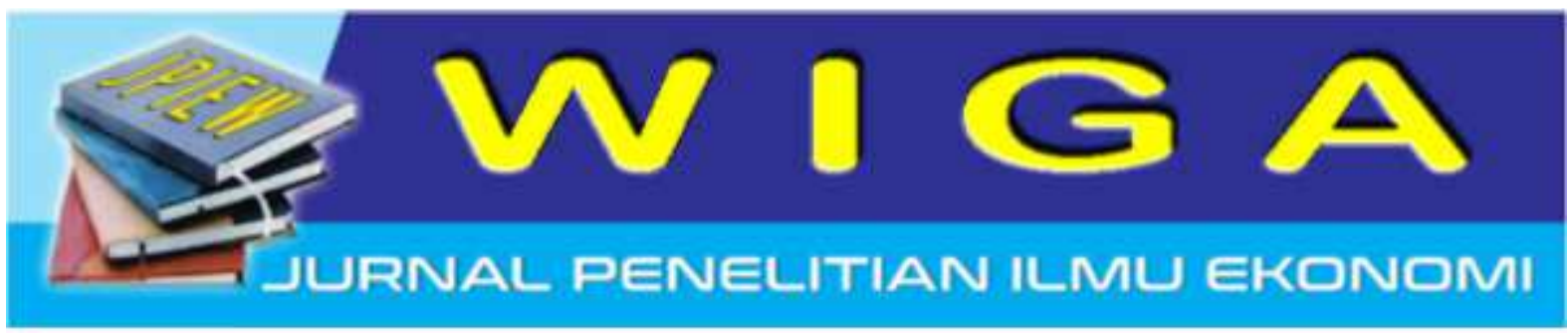

\title{
E-MARKETING SEBAGAI STRATEGI PEMASARAN UNTUK MENINGKATKAN PENJUALAN DI RUMAH PENGANTIN L'SINTA SIDOARJO
}

\author{
Laily Muzdalifah \\ Universitas Nahdhatul Ulama Sidoarjo \\ lailymuzdalifah.fe.unusida@gmail.com
}

\begin{abstract}
ABSTRAK
Wedding organizer merupakan suatu bisnis yang mana bergerak dalam bidang pelayanan jasa untuk pernikahan.Rumah pengantin L'Sinta Sidoarjo merupakan suatu bisnis di bidang wedding organizer yang mnyediakan berbagai jasa paket pelayanan wedding, mulai dari rias pengantin, dekor pelaminan, terop hingga pemesanan gaun pengantin. Semakin berkembangnya dunia bisnis dalam jasa pernikahan rumah pengantin L'Sinta pun mengalami penurunan penjualan pada tahun 2012 yaitu hanya sekitar 19 konsumen.Maka dengan adanya penurunan penjualan maka pihak owner menggunakan E-Marketing untuk meningkatkan penjualan tersebut.

Penelitian ini menggunakan metode penelitian komparatif.Teknik pengumpulan data untuk penelitian ini adalah menggunakan survei dan wawancara.Adapun hasil dari penelitian ini adalah terdapat kenaikan penjualan yang semakin tahun yang semakin meningkat dengan adanya penggunaan E-Marketing. Peningkatan penjualan tersebut yaitu ditahun 2013 terdapat 37 konsumen, tahun 2014 terdapat 45 konsumen, tahun 2015 sebanyak 49 konsumen dan tahun 2016 sebanyak 62 konsumen. Dengan demikian dapat disimpulkan bahwa penggunaan E-Marketing di rumah pengantin L'Sinta Sidoarjo sangat efektif untuk meningkatkan penjualan.
\end{abstract}

Kata Kunci: Wedding Organizer, Rumah Pengantin L'Sinta Sidoarjo, E-Marketing

\section{PENDAHULUAN}

\section{Latar Belakang}

E-Marketing adalah sebuah media yang mana sedang marak digunakan oleh semua kalangan.Bahkan media ini banyak digunakan untuk berbagai kegiatan dalam kehidupan sehari-hari.Salah satu kegunaan dari E-Marketing dalam kehidupan seharihari adalah maraknya penggunaannya dalam dunia bisnis.Bahkan hampir disemua sektor bisnis menggunakan E-Marketing untuk meningkatkan penjualan.Bahkan tidak sedikit dari perusahaan yang justru sangat bergantung pada E-Marketing untuk kegiatan pemasarannya.Menurut sumber yang dikutik dari Wikipedia Indonesia (https://id.wikipedia.org/wiki/Perdagangan elektronik) perusahaan yang menggunaan EMarketing yaitu seperti elevenia, tokopedia, lazada dan bukalapak.Bahkan pada saat ini 
adapun perusahaan transportasi yang menggunakan E-Marketing untuk kegiatan pemasarannya seperti Go-Jek, Uber Taxi dan sebagainya.

Sebuah bisnis yang menggunakan $E$ Marketing jelas memiliki target bisnis dengan membidik konsumen yang menggunakan E-Marketing dalam kehidupan sehari-hari. Bagi sebagian konsumen bahkan dengan menggunakan $E$ Marketing merupakan pilihan yang mudah, cepat tanpa harus berlama-lama untuk berbelanja disebuah tempat perbelanjaan.Perilaku konsumen yang seperti inilah yang menjadi salah satu faktor seorang pebisnis mengambil strategi dengan menggunakan E-Marketing untuk kegiatan pemasaran produknya.

L'Sinta Rumah Pengantin Sidoarjo merupakan suatu perusahaan jasa dibidang wedding organizer yang mana melayani paket pernikahan lengkap mulai dari rias pengantin, dekor, terop bahkan sampai catering. Sebelum menggunakan EMarketing sebagai media untuk memasarkan produknya L'Sinta Rumah Pengantin Sidoarjo hanya memasarkan produk jasanya melalui mulut ke mulut saja.Ada kalanya media yang digunakan sebagai promosi menggunakan brosur yang disebarkan ketika ada event.Namun dari tahun ke tahun seiring dengan perkembangan dunia bisnis dalam bidang jasa wedding organizer, maka kompetitor jasa wedding organizer pun semakin bertambah.Dengan bertambahnya kompetitor maka semakin menurun pula penjualan jasa pada L'Sinta Rumah Pengantin Sidoarjo.Penurunan penjualan tersebut khususnya pada tahun 2012 yang hanya sekitar 19 konsumen yang menggunakan jasa dari L'Sinta.

Sebelum menggunakan e-marketing, rumah pengantin L'Sinta Sidoarjo yang hanya menggunakan sarana promosi dari mulut ke mulut dan bahkan hanya brosur yang disebarkan disetiap event.Hal ini tidak terlalu efektif.Hal ini dikarenakan segmentasi, maupun target sasaran tidak tepat.Sehingga brosur banyak terbuang. Informasi belum tentu sampai pada target konsumen (calon pengantin). Dengan media promosi yang sangat terbatas itu akhirnya tidak banyak orang yang mengenal rumah pengantin L'Sinta.Hanya sekitar daerah Sidoarjo saja.Bahkan tidak sedikit konsumen yang bingung mengenai produk jasa yang ditawarkan oleh rumah pengantin L'Sinta.

Seiring berkembangnya E-Marketing dalam dunia bisnis L'Sinta berusaha meningkatkan penjualan dengan menggunakan E-Marketing.E-marketing yang dipilih yaitu dengan penggunaan social network yaitu berupa facebook dan instagram.Adapun alasan yang digunakan owner sehingga memilih e-marketing sebagai alternatif untuk peningkatan penjualan yaitu dengan semakin banyaknya pengguna smartphone.Bahkan hampir setiap orang yang memiliki smartphone memiliki media social berupa facebook, path, instagramdan lain sebagainya.Disamping itu biaya internet yang saat ini semakin murah akan membantu L'Sinta memanfaatkan $e$ marketing sebagai media promosinya. Dengan demikian akan menjadi peluang bagi L'Sinta untuk meningkatkan penjualannya melalui e-marketing.

Dengan semakin berkembangnya $E$ Marketingmaka dalam penelitian ini akan mengangkat judul yaitu 'E-Marketing Sebagai Strategi Pemasaran Untuk Meningkatkan Penjualan di Rumah Pengantin L'Sinta Sidoarjo'.

\section{Perumusan Masalah}

Berdasarkan latar belakang sudah diuraikan sebelumnya maka permasalahan 
yang teridentifikasi yaitu penurunan penjualan yang ada di Rumah Pengantin L'Sinta Sidoarjo dari tahun ke tahun dengan semakin berkembangnya kompetitor dalam bisnis wedding organizer. Untuk itu rumusan masalah dari penelitian ini adalah "Apakah dengan menggunakan E-Marketing dapat meningkatkan penjualan di Rumah Pengantin L'SintaSidoarjo ?"

\section{Tujuan dan Manfaat Penelitian}

Dengan melakukan observasi, pengambilan data, serta studi kasus dan pustaka, penulis melakukan penelitian dengan tujuan yang ingin dicapai sebagai berikut;

1. Mengetahui penggunaan EMarketinguntuk meningkatkan penjualan di Rumah Pengantin L'Sinta Sidoarjo.

Adapun manfaat dari penelitian ini adalah sebagai berikut :

1. Manfaat bagi perusahaan

Setelah dilakukan penelitian ini diharapkan menjadi masukan bagi perusahaan yang mana bisa mengatasi masalah-masalah atau kekurangankekurangan yang ada dalam perusahaan khususnya mengenai terjadinya penurunan penjualan dalam perusahaan tersebut.

2. Manfaat bagi program studi

Dengan adanya penelitian ini diharapkan sebagai tambahan referensi dan sebagai bahan perbandingan dengan penelitian sebelumnya khususnya pada variabel yang diambil dalam penelitian ini.

\section{TINJAUAN PUSTAKA}

\section{E-Marketing}

Definisi dari e-marketing menurut Candra Ahmadi dan Dadang Hermawan (2013:186) adalah bagian dari e-business yang memanfaatkan media elektronik untuk melakukan aktivitas marketing dalam upaya mencapai tujuan marketing.

Adapun penggunaan e-marketing adalah sebagai berikut :

1. Banner advertisement (iklan melalui banner) : iklan banner yang dipasang pada website penyedia iklan untuk memancing calon pembeli yang akan membeli produk.

2. Sponsorship

3. Classified listings (daftar produk terklasifikasi) : merupakan cara untuk memasang bisnis didepan orang yang siap untuk membeli produk . dalam klasifikasi online ini user dapat mencari produk dengan cepat melalui formulir pencarian yang sudah terindeks dalam basis data.

4. E-mail marketing (pemasaran melalui email) : hal ini bisa dilakukan dengan 3 cara. Pertama, dengan meletakkan iklan atau sebuah pesan dalam e-mail newsletter orang lain. Kedua, dengan secara langsung mendistribusikan e-mail kepada calon pelanggan. Ketiga, yaitu dengan menyediakan fasilitas e-mail subscriber pada situa.

5. Partnership/ affiliate marketing (pemasaran metode afiliasi) :yaitu para pengiklan menjual produknya secara online dapat membangun jaringan afiliasi yaitu melibatkan orang lain dalam penjualan produk.

6. Search engine markrting (pemasaran menggunakan mesin pencari).

7. Social networking (metode pemasaran menggunakan situs jejaring sosial) seperti facebook, Friendster, twitter bahkan untuk mengupload audio atau video melalui $w w w$.youtube.com. 
Menurut Candra ahmadi dan Dadang Hermawan (2013:190) adapun kelebihan dari E-Marketingyaitu :

Kelebihan :

1. Bisnis online bisa dijalankan dari mana saja yang penting ada komputer/ laptop yang terhubung internet.

2. Modal yang dibutuhkan relatif lebih sedikit

3. Bisnis bisa berjalan otomatis dengan bantuan software tertentu

4. Tidak butuh jumlah karyawan yang banyak

5. Tersedia banyak pilihan bisnis yang ada

\section{Wedding Organizer}

Menurut Ayi Wijayanti dalam situs websitenya

(http://tradisiperkawinan0.tripod.com/), Wedding Organizer adalah suatu jasa khusus yang membantu calon pengantin \& keluarga dalam perencanaan dan supervisi pelaksanaan rangkaian acara pesta pernikahan sesuai dengan jadwal yang telah ditetapkan.

Sedangkan menurut Indra dalam artikelnya http://www.viccasera.com/berita-174-apaitu-wedding-organizer.html) ,Wedding Organizer memfasilitasi, negosiasi dan koordinasi dengan pihak gedung/hotel dan supplier/vendor seperti Catering, dekorasi, fotografer, perias, grup musik, dan lain-lain.

Adapun ruang lingkup dari wedding organizer dalam website Ayi Wijayanti (http://tradisiperkawinan0.tripod.com/) adalah :

a. Memberikan input kepada calon pengantin mengenai hal-hal yang harusdiperhatikan dalam perencanaan dan pelaksanaan upacara pernikahan

b. Mencari lokasi resepsi (bila belum ada)

c. Menyusun budget

d. Membantu perencanaan mengenai tema, alur, dan dekorasi pesta e. Membuat Buku Program Acara Pernikahan (Skenario acara \& pengambilan gambar)

f. Mengkoordinasikan dan mengarahkan job description Panitia Keluarga

g. Fasilitasi, negosiasi dan koordinasi dengan pihak gedung/hotel dansupplier/vendor seperti catering, dekorasi, fotografer, perias, grup musik, dll

h. Pengurusan persyaratan akad nikah \& perizinan lain-lain

i. Menyusun jadwal kerja dan jadwal pembayaran

j. Mengatur setting ruangan dan flow tamu di rumah maupun di tempat resepsi

k. Supervisi pelaksanaan upacara pernikahan agar segala sesuatunya dapatberjalan dengan baik sesuai dengan rencana

1. Mengambil langkah-langkah pengamanan bila terjadi keadaan darurat (sebatas dengan kewenangan yang diberikan)

\section{L'Sinta Rumah Pengantin Sidoarjo}

L'Sinta rumah pengantin Sidoarjo merupakan sebuah bisnis dibidang wedding organizer.Pada bisnis ini menyediakan banyak penawaran jasa khususnya untuk pelayanan jasa pernikahan.Adapun kelengkapan yang bisa dilayani oleh L'Sinta rumah pengantin sidoarjo yaitu rias pengantin, persewaan terop, sound system, dekorasi pelaminan, foto $\&$ video pernikahan dan sebagainya.

\section{METODE PENELITIAN}

1. Metode penelitian

Metode penelitian ini menggunakan metode penelitian komparatif. Menurut Moh. Nasir (2014;47) yaitu data dikumpulkan setelah semua kejadian yang dikumpulkan telah selesai berlangsung. Dalam metode penelitian ini peneliti dapat melihat akibat 
dari suatu fenomena dan menguji hubungan sebab akibat dari data-data yang tersedia

2. Subjek dan objek penelitian

Subjek penelitian ini adalah konsumen dan owner rumah pengantin L'Sinta Sidoarjo sedangkan untuk objek penelitian yaitu rumah pengantin L'Sinta yang berada di Jl. Sekawan Molek II/D-9 Sidoarjo.

\section{Sumber data}

Dalam penelitian ini terdapat dua sumber data itu sumber primer dan sekunder.Sumber primer yaitu sumber yang diperoleh dari pemilik dari rumah pengantin L'SintaSidoarjo.Sedangkan untuk data sekunder yaitu perolehan data yang diambil berdasarkan E-Marketing yang selama ini digunakan oleh rumah pengantin L'SintaSidoarjo yakni mulai tahun 2011 hingga tahun 2016.

4. Metode pengumpulan data

Dalam penelitian ini untuk melakukan pengumpulan data yaitu menggunakan teknik wawancara dan observasi.

5. Waktu Pelaksanaan Penelitian

Penelitian ini dilaksanakan pada bulan September 2016 sampai dengan Desember 2016.

\section{PEMBAHASAN}

Rumah pengantin L'Sinta berdiri pada tahun 2004 bisnis yang bergerak dalam bidang Wedding Organizerini memang merupakan bisnis keluarga.Bisnis ini bermula dari owner Rumah Pengantin L'Sinta Sidoarjo yang kemudian bisnis ini diwariskan menurun kepada anak dari owner Rumah Pengantin L'Sinta Sidoarjo.Pada saat awal berdirinya Rumah Pengantin L'Sinta Sidoarjo merupakan bisnis awal yang hanya bergerak dibidang jasa rias pengantin saja.Tapi seiring dengan perkembangan bisnis di bidang Wedding Organizer, owner pun mengembangkan bisnisnya hingga ke Wedding Organizeryang mana dalam bisnis ini melayani konsumen dalam hal jasa pernikahan. Bukan hanya dalam segi rias pengantin saja, namun bisnis dari Rumah Pengantin L'Sinta Sidoarjo ini berkembang hingga melayani terop, dekorasi pelaminan hingga sound system dan pembuatan kebaya pernikahan.

Pada awal mula berdiri Rumah Pengantin L'Sinta Sidoarjo melakukan serangkaian promosi mulai dari penjualan dari mulut ke mulut hingga brosur yang dibagikan ketika ada event wedding.Namun seiring dengan berjalannya waktu, penjualan pun semakin menurun pada tahun 2012 dengan semakin banyaknya kompetitor khususnya dibidang Wedding Organizer.Pada tahun 2012 media sosial pun belum ramai seperti pada saat ini. Pada tahun 2011 jumlah konsumen L'Sinta sebanyak 24 orang dan semakin menurun di tahun 2012 yaitu hanya berjumlah 19 orang.

Untuk itu sebagai owner, memulai dengan menggunakan strategi E-Marketing yang mana digunakan untuk menaikkan penjualan pada Rumah Pengantin L'Sinta Sidoarjo.Rumah Pengantin L'Sinta Sidoarjo mulai menggunakan E-Marketing pada tahun 2013.Adapun e-marketing yang digunakan yaitu dengan menggunakan jejaring sosial atau social networking berupa facebook dan instagram. Setelah menggunakan e-marketing penjualan L'Sinta rumah pengantin mengalami peningkatan. Penggunaan e-marketing dianggap sebagai suatu media promosi yang sangat efektif yang mana bisa menjangkau konsumen diberbagai wilayah bahkan hingga sampai keluar kota. Adapun bentuk dari facebook dan instagram dari Rumah Pengantin L'SintaSidoarjo : 

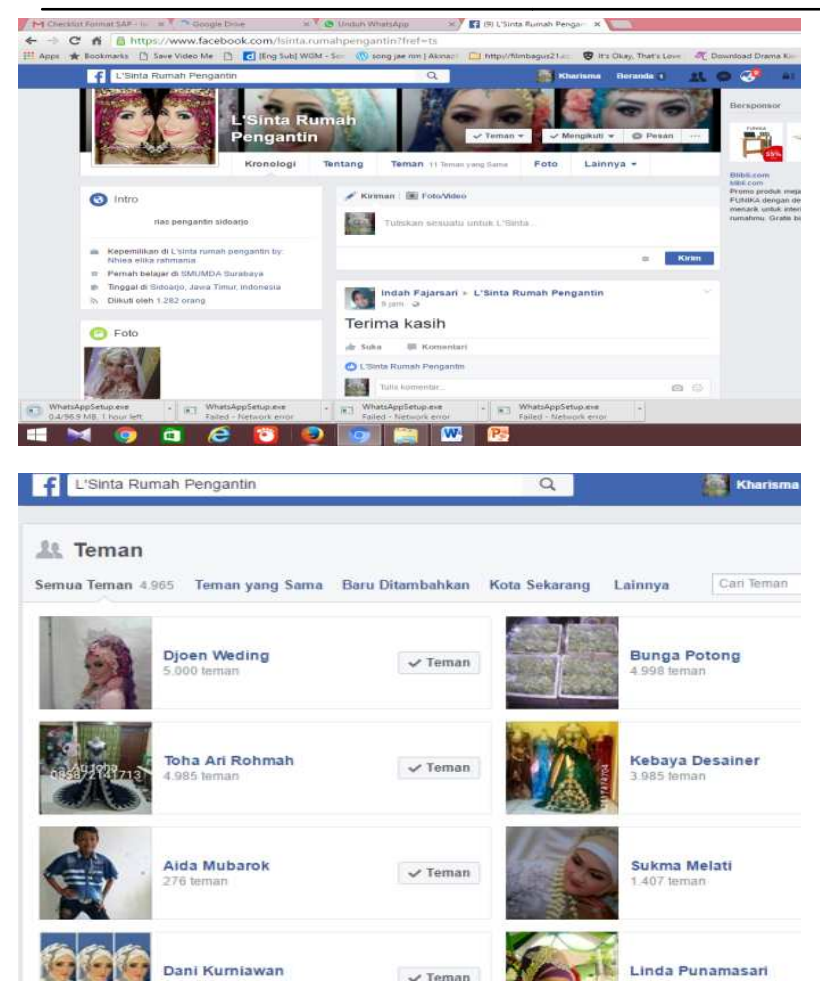

Berikut dibawah ini merupakan tampilan dari intagram dari rumah pengantin l'Sintasidoarjo :

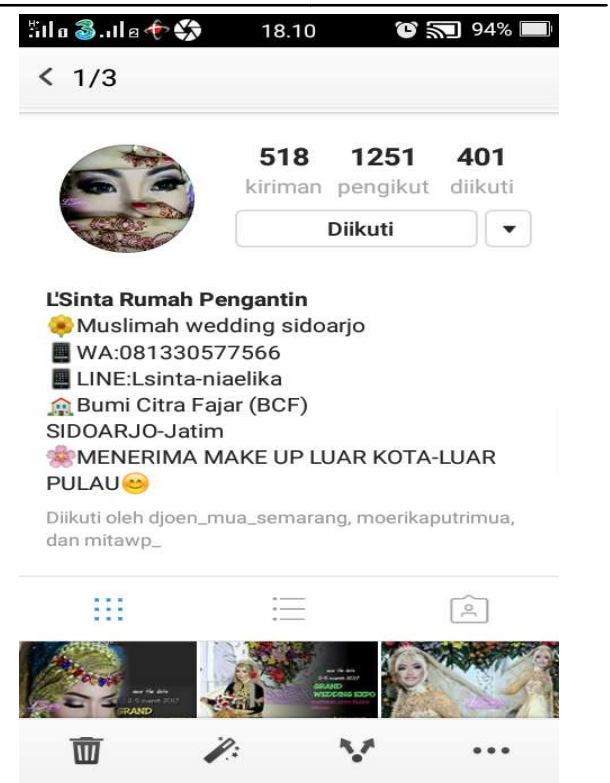

Penggunaan e-marketing yang dilakukan selama ini terus melakukan upload foto-foto pengantin secara rutin. Setiap kali event wedding yang diselenggarakan setelah itu pula foto-foto akan di upload baik melalui facebook maupun melalui instagram. Pada tahun 2013 rumah pengantin L'Sinta sidoarjo mulai menggunakan facebook sebagai media sosial untuk melakukan kegiatan promosinya.Sedangkan untuk media instragram L'Sinta rumah pengantin menggunakan mulai tahun 2013.Dalam akun instagramnya terdapat 1251 followers.Ada sebanyak 4.965 jumlah pertemanan yang ada difacebook.

Adapun rincian dari hasil penjualan baik sebelum maupun sesudah menggunakan e-marketingyaitu :

\begin{tabular}{|c|c|c|c|c|c|c|c|c|}
\hline \multirow{2}{*}{ Keterangan } & \multicolumn{9}{|c|}{ Tahun } \\
\cline { 2 - 9 } & \multicolumn{2}{|c|}{2013} & \multicolumn{2}{|c|}{2014} & \multicolumn{2}{c|}{2015} & \multicolumn{2}{c|}{2016} \\
\cline { 2 - 9 } & Offline & Online & Offline & Online & Offline & Online & Offline & Online \\
\hline $\begin{array}{c}\text { Hasil } \\
\text { Penjualan }\end{array}$ & 15 & 22 & 17 & 28 & 14 & 35 & 15 & 47 \\
\hline $\begin{array}{c}\text { Total } \\
\text { penjualan }\end{array}$ & \multicolumn{2}{|c|}{37} & \multicolumn{2}{|c|}{45} & \multicolumn{2}{|c}{49} & 62 \\
\hline
\end{tabular}

Dari table tersebut di atas dapat dijelaskan bahwa dengan menggunakan $e$ marketing melalui media sosial penjualan 
rumah pengantin L'Sinta mengalami peningkatan.Dari tahun 2013 ada sebanyak 37konsumen yang menggunakan jasa dari rumah pengantin L'Sinta berdasarkan informasi yang diperoleh dari facebook.Pada tahun ke-2 yaitu tahun 2014 terdapat 45konsumen yang menggunakan rumah pengantin L'Sinta.Tahun 2015 sebanyak 49 konsumen.Tahun 2016 terdapat62 konsumen yang menggunakan jasa rumah pengantin L'Sinta. Selain adanya peningkatan penjualan, banyak manfaat lain yang diperoleh setelah menggunakan e-marketing salah satunya yaitu dengan semakin mengenalnya banyak vendor-vendor dibidang jasa pernikahan. Profit yang diperoleh pun meningkat hingga 100\% setelah menggunakan e-marketing.

\section{KESIMPULAN DAN SARAN}

\section{KESIMPULAN}

Rumah Pengantin L'Sinta Sidoarjo merupakan salah satu dari sekian banyak bisnis wedding organizer yang menggunakan e-marketing untuk meningkatkan penjualan.Sebelum menggunakan strategi e-marketing ini Rumah Pengantin L'Sinta Sidoarjo mengalami penurunan penjualan.Adapun kenaikan penjualan setelah menggunakan $e$ marketing yaitu sebanyak 100\%.Dengan demikian dapat disimpulkan bahwa emarketing merupakan salah satu strategi yang dapat digunakan untuk menaikkan penjualan dalam sebuah bisnis.

\section{SARAN-SARAN}

Berdasarkan kesimpulan yang sudah dijelaskan sebelumnya bahwa selain penggunaan e-marketing dengan menggunakan media jejaring sosial atau social networking dapat dikembangkan pula media untuk meningkatkan penjualan dengan menggunakan situs www maupun menggunakan blog. Dengan semakin bertambahnya e-marketing yang digunakan maka akan semakin meningkatkan pula penjualan di Rumah Pengantin L'Sinta Sidoarjo.

Selain menambah adanya jaringan $e$ marketing dalam menaikkan penjualan Rumah Pengantin L'Sinta Sidoarjo dapat mencoba menaikkan penjualan dari segi pelayanan yang diperluas lagi dalam ebusiness misalnya dengan pembayaran via online, katalog via online dan sebagainya.

\section{DAFTAR PUSTAKA}

Ahmadi, Candra dan Dadang Hermawan. 2013. E-Business \& E-Commerce.Yogyakarta : Andi.

http://tradisiperkawinan0.tripod.com/. Diakses : 15 Agustus 2016

http://www.viccasera.com/berita-174-apa-ituwedding-organizer.html. Diakses : 15 Agustus 2016

https://id.wikipedia.org/wiki/Perdagangan_elektr onik, diakses : 12 Agustus 2016

https://web.facebook.com/lsinta.rumahpengantin ?fref=ts, diakses : 12 Agustus 2016

Instagram L'Sinta Rumah Pengantin

Nazir, Moh. 2014. Metode Penelitian. Bogor : ghalia Indonesia.

Sugiyono. 2014. Metode Penelitian Bisnis. Bandung : Alfabeta. 